\title{
Erratum to: A Delphi process to address medication appropriateness for older persons with multiple chronic conditions
}

Terri R. Fried ${ }^{1,2^{*}}$, Kristina Niehoff', Jennifer Tjia ${ }^{3}$, Nancy Redeker ${ }^{4}$ and Mary K. Goldstein ${ }^{5,6}$

\section{Erratum}

After publication of this work [1], it was noted that there was an error within Fig. 2. Within this figure the word "problems" was omitted from the statement "Medications for which there are no indications, including medications stated at an earlier time for self-limited problems". Figure 2 has been corrected in the original article and is also included correctly below.

\footnotetext{
* Correspondence: terri.fried@yale.edu

${ }^{1}$ Clinical Epidemiology Research Center, VA Connecticut Healthcare System,

950 Campbell Avenue, West Haven, CT 06516, USA

${ }^{2}$ Department of Medicine, Yale School of Medicine, 333 Cedar Street, New

Haven, CT 06510, USA

Full list of author information is available at the end of the article
} 


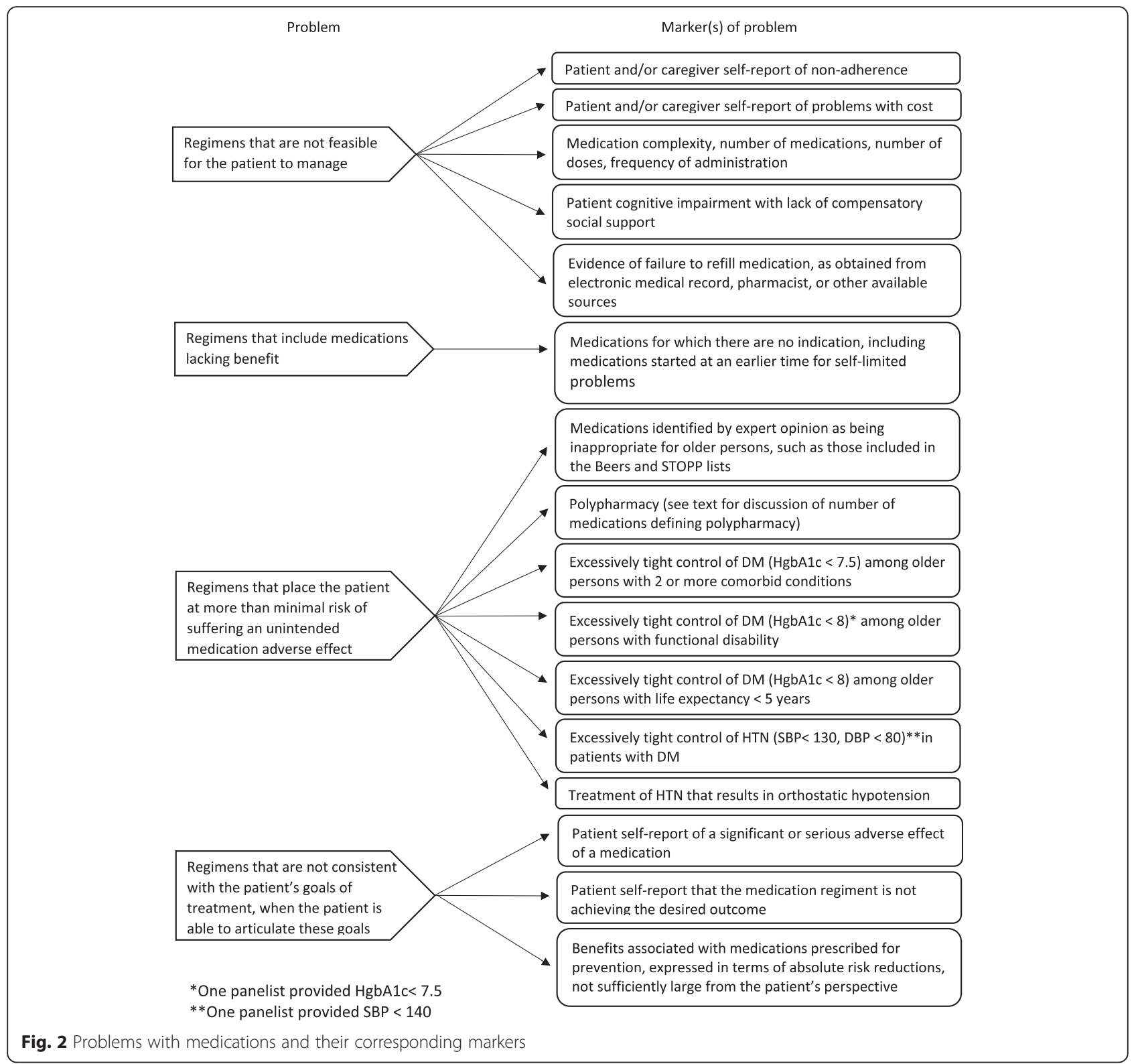

\section{Author details}

${ }^{1}$ Clinical Epidemiology Research Center, VA Connecticut Healthcare System, 950 Campbell Avenue, West Haven, CT 06516, USA. ²Department of

Medicine, Yale School of Medicine, 333 Cedar Street, New Haven, CT 06510,

USA. ${ }^{3}$ Department of Quantitative Health Sciences, UMass Medical School, 368 Plantation Street, Worcester, MA 01605, USA. ${ }^{4}$ Yale School of Nursing, Yale University West Campus, P.O. Box 27399, West Haven, CT 06516, USA. ${ }^{5}$ Palo Alto Geriatrics Research Education and Clinical Center (GRECC), Veterans Affairs Palo Alto Health Care System, GRECC 182-B, 3801 Miranda Avenue, Palo Alto, CA 94304, USA. ${ }^{6}$ Center for Primary Care and Outcomes Research (PCOR), Stanford University, 117 Encina Commons, Stanford, CA 94305, USA.

Received: 8 June 2016 Accepted: 8 June 2016

Published online: 16 June 2016

\section{Reference}

1. Fried TR, Niehoff K, Tija J, Redeker N, Goldstein MK. A Delphi process to address medication appropriateness for older persons with multiple chronic conditions. BMC Geriatrics. 2016;16:67. doi:10.1186/s12877-016-0240-3. 